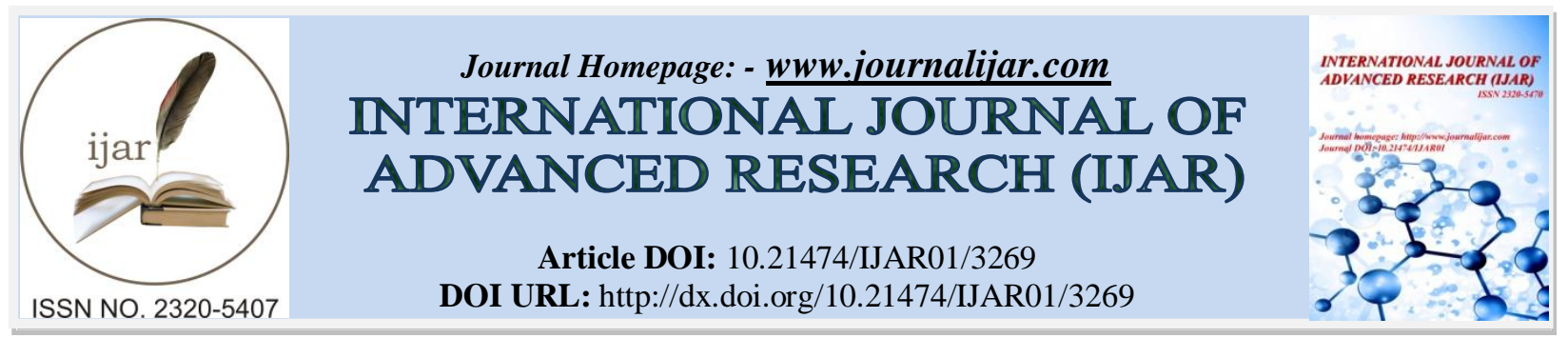

RESEARCH ARTICLE

\title{
SERUM GALECTIN-4 (GAL-4) IN PATIENTS WITH GASTRIC ADENOCARCINOMA: ACTIVE PLAYER IN THE FIELD.
}

\begin{abstract}
Ahmed Hamouda Arnaout ${ }^{1}$ and Lamya Mahmoud Ibrahim ${ }^{2}$.
1. Department of Internal Medicine, Faculty of Medicine, Zagazig University, Egypt.

2. Department of Clinical Pathology, Faculty of Medicine, Mansoura University, Egypt.
\end{abstract}

\section{Manuscript Info}

Manuscript History

Received: 23 December 2016

Final Accepted: 27 January 2017

Published: February 2017

Key words:-

Galectin-4, gastric cancer, validity.

\section{Abstract}

Introduction: Galectin- 4 is one of a $\beta$-galactosides binding proteins family that recognize a variety of glycan-containing proteins at the cell surface and are overexpressed in various tumors, including gastric cancer. Galectin-4 overexpression as well as changes in their subcellular distribution has been associated with gastric cancer progression and poor prognosis. It may provide diagnostic molecular markers for gastric cancer as well as clues for developing therapeutic targets on individual basis.

Aim of the study: To detect the levels of GAL-4 in the sera of healthy people and patients with gastric cancer and also, to investigate the validity of using GAL-4 as a specific diagnostic marker of gastric cancer.

Patients and methods: 25 gastric cancer patients were included in this study. They were among patients who attending the Endoscopy Department, during the period from September 2015 to March 2016. In addition, 15 apparently healthy people were chosen as a healthy control group. For these two groups, serum level of GAL-4 using ELISA technique was carried out.

Results: There was a statistically significant difference in serum level of GAL-4 among gastric adenocarcinoma patients in comparison to healthy controls ( $\mathrm{p} \leq 0.001$ ), using receiver operating characteristic curve (ROC) area, serum GAL-4 has high area under the curve (0.924) with a cut off value equal to or above $0.42 \mathrm{ng} / \mathrm{ml}$ which was associated with the highest sensitivity $(100 \%)$.

Conclusions: Serum levels of GAL-4 were significantly higher in patients with malignant gastric adenocarcinoma which may confirm a possible role of this marker in the pathogenesis of the disease, furthermore the highest sensitivity and best accuracy obtained from serum GAL-4 was by using a cut off values equal to or above $0.42 \mathrm{ng} / \mathrm{ml}$. So, GAL-4 may be promising new diagnostic tools especially at early stages and among patients at high risk.

Copy Right, IJAR, 2017,. All rights reserved. 


\section{Introduction:-}

Gastric cancers are one of the most frequent fatal malignancies in the world (1) and have a wide pathological and biological variety (2). However, accurate molecular pathways of gastric carcinogenesis and clinical progression are yet to be clarified. So that, a comprehensive proteins expression profile of gastric cancers is necessary to provide a diagnostic molecular markers for gastric cancer as well as to clue for developing therapeutic targets on individual basis (3).

Despite a major decline in incidence and mortality over several decades, stomach cancer is still has a 10-fold variation in incidence between populations at the highest and lowest risk. The incidence is particularly high in East Asia, Eastern Europe, and parts of Central and South America, and it is about twice as high among men than among women; It is estimated about 21,600 men and women (13,230 men and 8,370 women) will be diagnosed with it and 10,990 men and women will die from gastric cancer in $2013(4,5)$. Galectins are a group of proteins that bind $\beta$ galactosides through evolutionarily conserved sequence elements of the carbohydrate recognition domain (CRD) (6, 7,8 ), as galectins are expressed by different immune and inflammatory cells, therefore, they can affect and regulate different responses produced by the host against tumors. In addition, galectins are released by tumors and can modulate a variety of inflammatory responses $(9,10)$ either by amplification of the inflammatory responses, including regulation of leukocyte survival and function or activation of homeostatic signals to shut off immune effecter functions. Like many other cytokines and growth factors, galectins may exhibit a 'double-edge sword' effect depending on many different intrinsic factors like microenvironment $(11,12)$. Moreover some galectins released by the tumor might help the tumor to avoid the immune surveillance (13).

\section{Patients and Methods:}

This study involved 25 cases with gastric cancer were included in the study. Their age ranged between 34 to 77 years with a mean of $60.4 \pm 10.7$ years $( \pm$ SD). On the other hand a total of 15 healthy controls were included in the study. Their age ranged between 32 to 76 years with a mean of $53.6 \pm 10.9$ years $( \pm$ SD). Those patients were diagnosed clinically, radiologically, cytologically, and histopathologically, they were among patients who attending the Endoscopy Department, during the period from September 2015 to March 2016. Also, 15 apparently healthy persons were chosen as a healthy control group. For these two groups, serum level of GAL-4 using sandwich ELISA technique was carried out.

Galectin-4 (Gal-4) ELISA KIT (Antibodies-Online.Com): The kit was a sandwich enzyme immunoassay for in vitro quantitative measurement of GAL-4 in human serum, plasma \& other biological fluids (14).

Statistical analysis was done using SPSS (Statistical Package for Social Sciences). The majority of the outcome quantitative variables were non-normally distributed. Such variables are described by median and interquartile range. Statistical significance of differences between averages for parameters of normal distribution was assessed using the Student's t-test, and the difference in median of a quantitative non-normally distributed variable between 2 groups was assessed by nonparametric Mann-Whitney test.

The statistical significance, direction and strength of linear correlation between 2 quantitative variables, one of which being non-normally distributed was measured by Spearman's rank linear correlation coefficient. P value less than the 0.05 level of significance was considered statistically significant (15).

\section{Results:-}

The ranges, median and mean value of serum GAL-4 in blood of gastric cancer patient and control groups are shown in table 1; there was a statically significant difference in the serum level of GAL-4 between gastric adenocarcinoma patients and healthy controls ( $\mathrm{p}<0.001$ ), as shown in (table 1 and figure 1 ).

Table 1:- The ranges, median and mean values of serum GAL-4 in blood of gastric cancer patients and control groups.

\begin{tabular}{|l|l|l|l|l|l|}
\hline \multicolumn{2}{|c|}{ Serum Galactin-4 } \\
\hline Case-control comparison & $\mathrm{N}$ & Range & Median & Mean rank & Interquartile range \\
\hline Controls (Gastric & 15 & $(0.22-1.7)$ & 0.50 & 9.90 & $(0.28-0.61)$ \\
\hline Cases & 25 & $(0.46$ & 2.97 & 26.86 & $(0.85-16.96)$ \\
Adenocarcinoma) & & $41.41)$ & & & \\
\hline
\end{tabular}




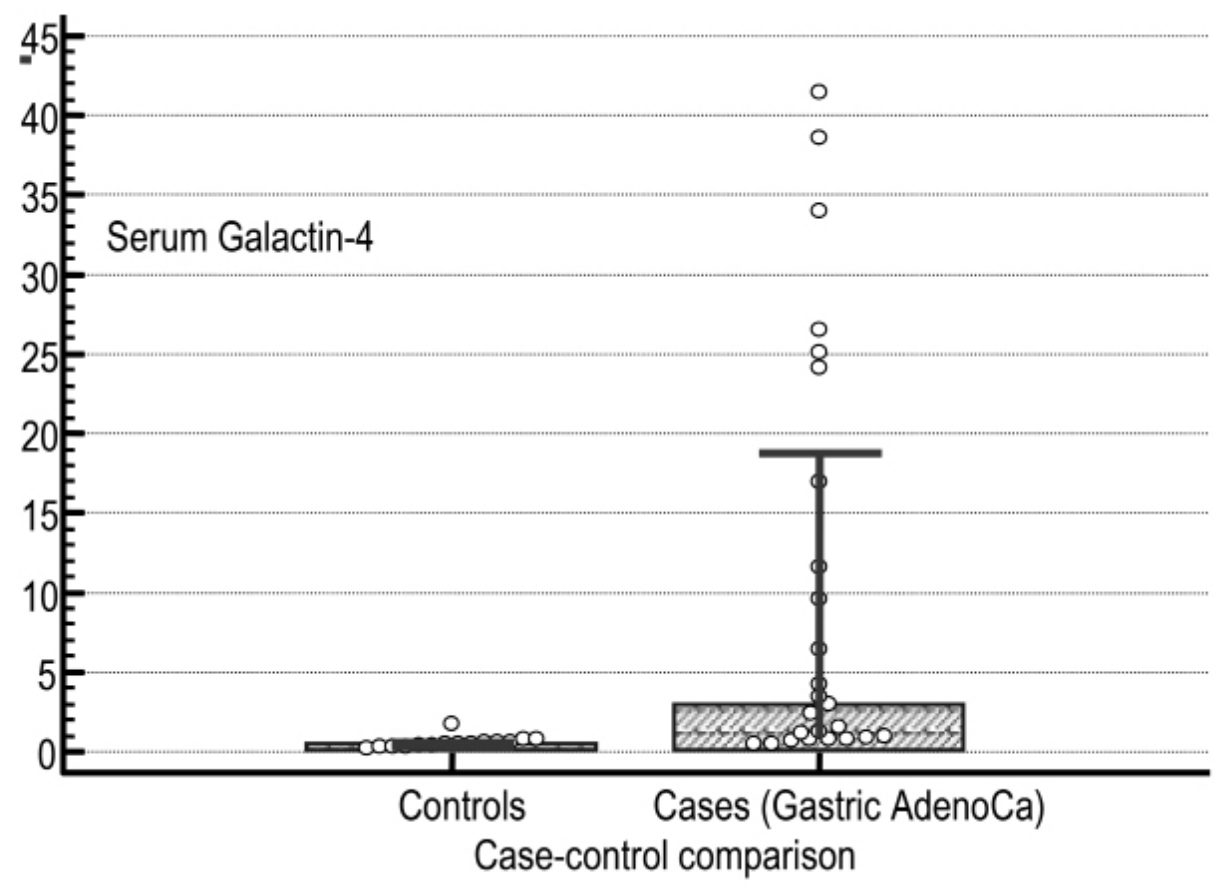

Figure 1:- Differences in median values of serum GAL-4 between 2 study groups.

As shown in (table 2 and figure 2) the large area under the ROC curve for galectin-4 (0.924) which was significantly higher than (0.5) area.

Table 2:- ROC area for galactin-4 as a predictor.

\begin{tabular}{|l|l|l|}
\hline & AUC & P \\
\hline Serum Galactin-4 & 0.924 & $<0.001$ \\
\hline
\end{tabular}

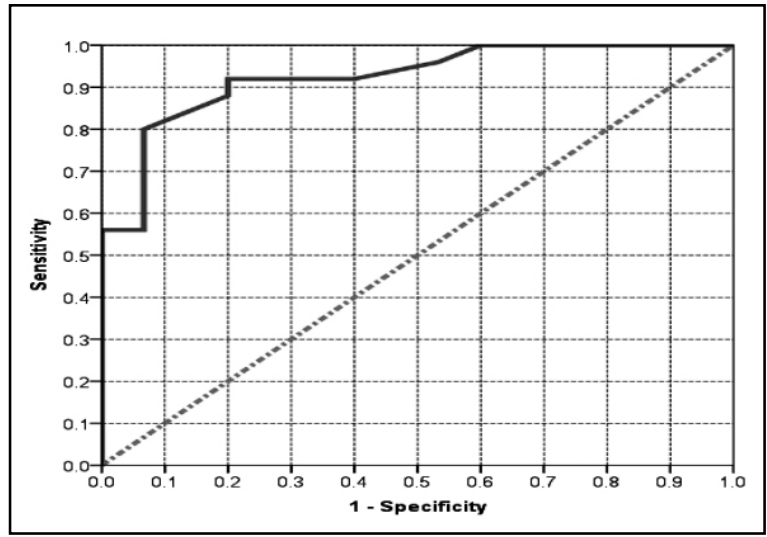

Figure 2:- ROC curve showing the trade-off between sensitivity (rate of true positive) and specificity (rate of false positive) for galactin-4 when used as a predictor test for advanced gastric adenocarcinoma.

The cut-off value of serum GAL-4 associated with highest sensitivity (100\%) was equal to or above $0.42 \mathrm{ng} / \mathrm{ml}$. Testing negative at this cut-off value (serum level $<0.42 \mathrm{ng} / \mathrm{ml}$ ) would exclude a possible diagnosis of gastric adenocarcinoma with $100 \%$ confidence (NPV "negative predictive value" $=100 \%$ ). The cut- off value associated with highest specificity (100\%) was set at equal to or above $2.07 \mathrm{ng} / \mathrm{ml}$; this cut-off value has an average sensitivity (56\%). Testing positive at this high cut-off value (obtaining a serum GAL-4 concentration of 2.07 and above ng/ml) would establish a diagnosis of gastric adenocarcinoma with $100 \%$ confidence in any clinical context (any pretest 
probability). The optimum cut- off value of serum GAL-4 in the context of case- control differentiation is the cut-off value that can classify tested subjects into gastric adenocarcinoma cases and control groups with the highest accuracy possible. The optimum cut-off value was set at equal to or above $0.63 \mathrm{ng} / \mathrm{ml}$, therefore the sensitivity was $92 \%$ and specificity was $80 \%$ at this cut off value.

Table 3:- The validity parameters of galactin- 4 when used as test to predict cases with advanced gastric adenocarcinoma differentiating them from healthy controls.

\begin{tabular}{|c|c|c|c|c|c|c|c|}
\hline & \multirow{2}{*}{$\begin{array}{l}\text { Matthew's } \\
\text { correlation } \\
\text { coefficient }\end{array}$} & \multicolumn{2}{|c|}{$\begin{array}{ll}\text { PPV at } & \text { pretest } \\
\text { probability }=\end{array}$} & \multirow{2}{*}{$\begin{array}{l}\text { NPV at } \\
\text { pretest } \\
\text { probability } \\
=10 \%\end{array}$} \\
\hline $\begin{array}{l}\text { Positive if } \geq \\
\text { cut-off value }\end{array}$ & Sensitivity & Specificity & Accuracy & & $50 \%$ & $90 \%$ & \\
\hline \multicolumn{8}{|c|}{ Serum Galactin-4 } \\
\hline $\begin{array}{l}0.42 \text { (highest } \\
\text { sensitivity) }\end{array}$ & 100.0 & 40.0 & 77.5 & 0.542 & 62.5 & 93.8 & 100.0 \\
\hline 0.48 & 96.0 & 46.7 & 77.5 & 0.516 & 64.3 & 94.2 & 99.1 \\
\hline 0.54 & 92.0 & 60.0 & 80.0 & 0.564 & 69.7 & 95.4 & 98.5 \\
\hline 0.59 & 92.0 & 66.7 & 82.5 & 0.62 & 73.4 & 96.1 & 98.7 \\
\hline 0.63 (optimum) & 92.0 & 80.0 & 87.5 & 0.731 & 82.1 & 97.6 & 98.9 \\
\hline 0.69 & 88.0 & 80.0 & 85.0 & 0.68 & 81.5 & 97.5 & 98.4 \\
\hline 0.75 & 84.0 & 86.7 & 85.0 & 0.692 & 86.3 & 98.3 & 98.0 \\
\hline 0.79 & 80.0 & 93.3 & 85.0 & 0.711 & 92.3 & 99.1 & 97.7 \\
\hline 0.83 & 76.0 & 93.3 & 82.5 & 0.671 & 91.9 & 99.0 & 97.2 \\
\hline 0.90 & 72.0 & 93.3 & 80.0 & 0.633 & 91.5 & 99.0 & 96.8 \\
\hline 1.04 & 68.0 & 93.3 & 77.5 & 0.597 & 91.1 & 98.9 & 96.3 \\
\hline 1.20 & 64.0 & 93.3 & 75.0 & 0.561 & 90.6 & 98.9 & 95.9 \\
\hline 1.41 & 60.0 & 93.3 & 72.5 & 0.527 & 90.0 & 98.8 & 95.5 \\
\hline 1.62 & 56.0 & 93.3 & 70.0 & 0.493 & 89.4 & 98.7 & 95.0 \\
\hline $\begin{array}{l}2.07 \text { (Highest } \\
\text { specificity) }\end{array}$ & 56.0 & 100.0 & 72.5 & 0.568 & 100.0 & 100.0 & 95.3 \\
\hline
\end{tabular}

\section{Discussion:-}

The study showed that the median serum GAL-4 was significantly higher among gastric cancer patients in comparison to healthy controls $(\mathrm{p}<0.001)$. These findings were in agreement with a study conducted by Barrow et al (2011) who reported that the concentrations of free circulating galectins-2,-3,-4and-8 were all markedly increased in the blood circulation of patients with gastrointestinal tract cancer and, in particular, those with metastasis. The presence of these galectins promotes cancer cell adhesion to vascular endothelial cells by interaction with the Thomsen-Friedenreich (TF) disaccharide on cancer associated mucin protein-1 (MUC1) (16). Furthermore, a series of experimental and clinical data demonstrated a correlation between galectins expression and tumor progression and metastasis. Galectins function inside the cells in both carbohydrate dependent and in dependent manners and can regulate signal transduction as well as epithelial morphogenesis via an effect on centrosome biology (17). This study showed that serum GAL-4 was associated with high validity when used as a predictor test for advanced gastric adenocarcinoma. The high validity is evident from the large area under the ROC curve $(0.924)$ which is significantly higher than (0.5) area associated with an equivocal test. In order to study the validity of serum GAL-4 in differentiating between gastric cancer patients from healthy controls, the present study showed that in a patient with serum GAL-4 equal to or above $0.42 \mathrm{ng} / \mathrm{ml}$ (cut off value) one can establish the diagnosis of gastric cancer with $62.5 \%$ confidence (PPV) in a clinical situation where the present probability of tumor is $50 \%$, or $93.8 \%$ confidence (PPV) in a clinical situation with high pretest probability (90\%). Testing negative at this cut off value would exclude a diagnosis of gastric cancer with $100 \%$ confidence (NPV) in a clinical setting were the primary diagnosis of tumor is of small probability (10\%pretest probability). In another words, if a physician has a $(50 \%)$ clinical suspicion about a patients as a case of gastric mass and send them for testing serum level of galectin-4 and the result was positive, this test gives $62.5 \%$ confidence for a physician to establish the diagnosis, but if that physician has $90 \%$ clinical suspicion about the patient to be a case of gastric cancer and the result of serum level of galectin-4 was positive, these results give a $93.8 \%$ confidence for the physician to establish the diagnosis; while if a physician suspicion was $10 \%$ for a patient to be a case of gastric cancer and want to exclude the diagnosis for the tumor, serum galectin- 4 negative result can give $100 \%$ confidence to exclude the diagnosis. A subject with serum 
concentration of GAL-4 less than $0.63 \mathrm{ng} / \mathrm{ml}$ is considered as compatible with normal value (negative test) while a value of $0.63 \mathrm{ng} / \mathrm{ml}$ and above is considered abnormally high (positive test for gastric adenocarcinoma), within the working range of the test $(0.42-2.07 \mathrm{ng} / \mathrm{ml})$. Testing negative at the optimum cut- off value would exclude a possible diagnosis of gastric malignancy with $98.9 \%$ confidence in a clinical context, when gastric cancer is highly unlikely on clinical bases (pretest probability is $10 \%$ only), Testing positive at the optimum cut-off value would establish the diagnosis of gastric adenocarcinoma with $82 \%$ confidence in a clinical context of equal odds pretest probability for gastric adenocarcinoma; when the pretest probability of having this disease is increased to $90 \%$ (high clinical suspicion) having a positive test would be almost diagnosis raising the confidence in the diagnosis of gastric malignancy to $97.6 \%$.

The mechanism for the increased circulating galectins in patients with gastric cancer is unclear. Members of galectins family are expressed by many types of human cells including epithelial, endothelial and immune cells including monocyte, macrophage and lymphocytes (16). The expressions of galectins in immune cells are heavily influenced by inflammatory regulator and also by differentiation and activation $(18,19)$. Many pro-inflammatory cytokines including TNF- $\alpha$, IL-1, IL-8, and GM-CSF are up regulated in cancerous conditions and their presences may cause the immune cells to secrete more galectins in the blood stream $(16,20)$.

Finally, targeting the actions of circulating galectins in the bloodstream of gastric cancer patients may represents a very promising therapeutic strategy for preventing metastasis (21).

\section{References:-}

1. Neugut, A. I., Hayek, M., and Howe, G. (1996); Epidemiology 1. of gastric cancer. Semin. Oncol. 23: 281291.

2. Werner, M., Becker, K. F., Keller, G., and Hofler, H. (2001); 2. Gastric adenocarcinoma: pathomorphology and molecular pathology. J. Cancer Res. Clin. Oncol. 127: 207- 216.

3. Kim B., Bang S., Lee S., et al., (2003); Expression Profiling 3. and Subtype-Specific Expression of Stomach Cancer. Cancer Res; 63: 8248-8255.

4. ACCC (2012); Gastric Cancer Quick Facts, Association of 4. Community cancer centers, http://www.accccancer.org/education/GastricCancer-Facts.asp.

5. American Cancer Society: Cancer Facts and Figures 5. (2013); Atlanta, Ga: American Cancer Society, 2013.http://www.cancer.gov/cancertopics/pdq/prevention/gastric/HealthProfessional/page2\#Reference2.5.

6. Barondes SH, Castronovo V, Cooper DNW, Cummings RD, 6. Drickamer K, Feizi T, Gitt MA, Hirabayashi J, Hughes C, Ken-ichi K, Leffler H, Liu FT, Lotan R, Mercurio AM, Monsigny M, Pillai S, Poirer F, Raz A, Rigby PWJ, Rini JM, Wang JL (1994); Galectins: a family of animal $\beta$-galactoside-binding lectins. Cell; 76:597-598.

7. Leffler H, Carlsson S, Hedlund M, Qian Y, Poirier F (2004); 7. Introduction to Galectins, Glycoconjugate Journal; 19:433-440.

8. Balan V, Makker P N, RAZ A (2010); Galectins as Cancer 8. Biomarkers, Cancers, 2, 592-610.

9. Rabinovich G A, Toscano M A, Ilarregui J M, Rubinstein 9. N (2004); Shedding light on the immunomodulatory properties of galectins: novel regulators of innate and adaptive immune responses. Glycoconj J; 19: 565-573.

10. Young A R, Meeusen E N (2004); Galectins in parasite 10. Infection and allergic inflammation, Glycoconjugate journal; 19: 601-606.

11. Nakahara S, Oka N, Raz A (2005); on the role of galectin-3 11. in cancer apoptosis. Apoptosis; 10:267-275.

12. Rabinovich G A, 12. Liu FT, Hirashima M, Anderson A (2007) an emerging role for galectins in tuning the immune response: lessons from experimental models of inflammatory disease, autoimmunity and cancer. Scand J Immunol; 66:143-158.

13. Liu F T, Rabinovich GA (2005); Galectins as modulators of tumor progression. Nat Rev Cancer; 5:29-41.

14. Antibodies - online. com: GALECTIN 4 (GAL-4) ELISA KIT. http://www.antibodies-online.com/

15. Sorlie DE. (1995); Medical biostatistics and epidemiology: Examination and Board review. First ed, Norwalk, Connecticut, Appleton and Lange: $47-88$.

16. Barrow H, Guo X, Wandall HH, Pedersen JW, Fu B, Zhao Q, Chen C, Rhodes JM, Yu LG (2011); Serum Galectin-2, -4, and -8 Are Greatly Increased in Colon and Breast Cancer Patients and Promote Cancer Cell Adhesion to Blood Vascular Endothelium. Clin Cancer Res.; 17(22):7035-46. 
17. Dumic J, Dabelic S, Flogel M (2006); Galectin-3: An open-ended story. Biochim Biophys Acta.; 1760: 616635.

18. Nangia-Makker P, Ochieng J, Christman JK, Raz A (1993); Regulation of the expression of galactosidebinding lectin during human monocytic differentiation. Cancer Res.; 53: 5033-7.

19. Joo HG, Goedegebuure PS, Sadanaga N, Nagoshi M, von Bernstorff W, Eberlein TJ (2001); Expression and function of galectin-3, a beta-galactoside-binding protein in activated T lymphocytes. J Leukoc Biol; 69:55564.

20. Miles FL, Pruitt FL, van Golen KL, Cooper CR (2008); 20. Stepping out of the flow: capillary extravasation in cancer metastasis. Clin Exp Metastasis.; 25: 305-24.

21. Duckworth CA, Yu LG (2012); Galectins and disease 21. Implications for targeted therapeutics in: Galectins in the blood circulation: potential therapeutic targets of cancer metastasis. ACS Symposium series, American Chemical Society: Washington. Chapter 18, pp. 309-322. 